\title{
Extremely High Panesophageal Pressurization in Type II Achalasia
}

\author{
Hyung Hun Kim* and Myung-Gyu Choi \\ Department of Internal Medicine, The Catholic University of Korea College of Medicine, Seoul, Korea
}

A 74-year-old man came to our motility clinic with a complaint of difficulty in swallowing solid food and liquid that had seriously progressed for the past 2 months. Two years ago, he developed intermittent swallowing difficulty but maintained usual daily life without serious problems. After then, the symptom abruptly progressed for the last 2 months before visit. He was not able to swallow anything for two days before coming to our clinic. Esophagogastroscopy showed the very narrow and tight lower esophagus (Fig. 1A) and the tight esophagogastric junction con- stricting an endoscope strongly (Fig. 1B). Advancing an endoscope was difficult and even needed much force. Endoscopic ultrasonography demonstrated thickened esophageal inner circular muscle, approximately $2.5 \mathrm{~mm}$, at $40 \mathrm{~cm}$ from upper incisor (Fig. 2A). High-resolution manometry revealed elevated mean integrated relaxation pressure of $21.8 \mathrm{mmHg}$ with panesophageal pressurization in all ten swallows (Fig. 2B). The pressure of the esophageal body during swallowing was extremely high; elevated up to $150.0 \mathrm{mmHg}$ at the lower esophagus (Fig. 2B). According

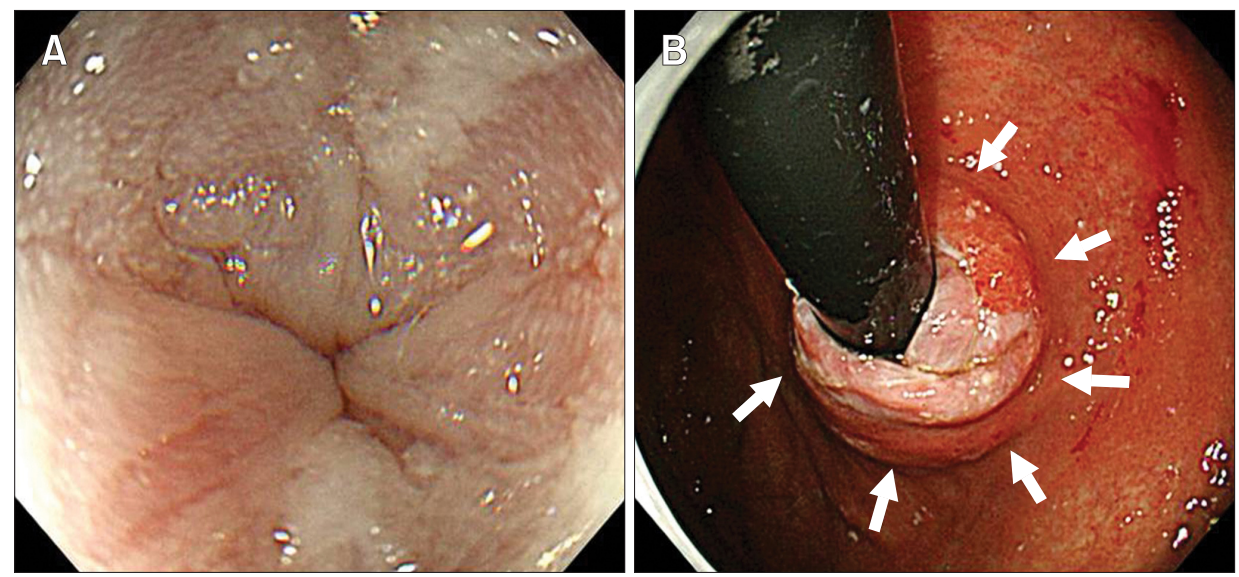

Figure 1. Endoscopic findings. (A) Esophagoscopy reveals a tightly narrowed distal esophagus at $40 \mathrm{~cm}$ from the upper incisor, even with full aeration. It was very hard to advance an endoscope through the lower third of the esophagus. (B) Retroflexion view shows that esophagogastric junction constricts an endoscope tightly (arrows).

Received: February 13, 2013 Revised: March 7, 2013 Accepted: March 11, 2013

(c) This is an Open Access article distributed under the terms of the Creative Commons Attribution Non-Commercial License (http://creativecommons. org/licenses/by-nc/3.0) which permits unrestricted non-commercial use, distribution, and reproduction in any medium, provided the original work is properly cited.

*Correspondence: Hyung Hun Kim, MD

Division of Gastroenterology, Department of Internal Medicine, The Catholic University of Korea College of Medicine, Seoul St. Mary's Hospital, 222, Banpo-daero, Seocho-Gu, Seoul 137-701, Korea

Tel: +82-2-2268-1222, Fax: +82-2-2258-2089, E-mail: drhhkim@gmail.com

Financial support: None.

Conflicts of interest: None.

Author contributions: Hyung Hun Kim wrote this paper as the first author. Myung-Gyu Choi reviewed the manuscript. 

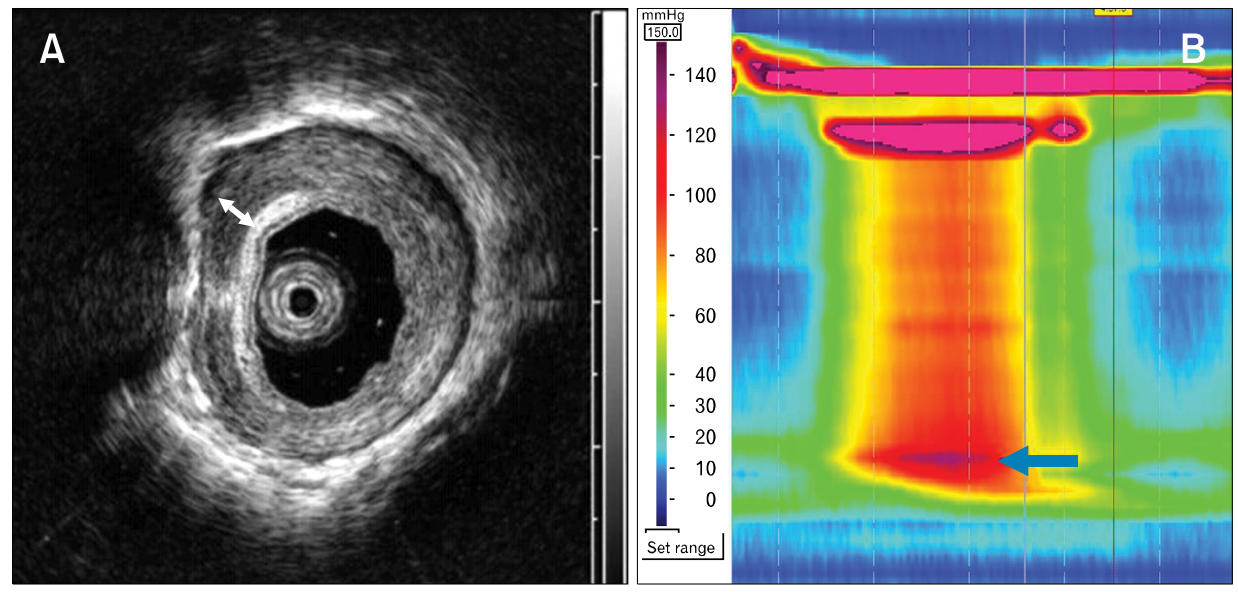

Figure 2. Presentation by endoscopic ultrasonography and high resolution manometry. (A) EUS demonstrates very thick esophageal inner circular muscle; approximately $2.5 \mathrm{~mm}$ (arrow) at $40 \mathrm{~cm}$ from the upper incisor. (B) High-resolution manometry presents increased integrated relaxation pressure, $26.8 \mathrm{mmHg}$, and extremely high panesophageal pressurization. Dark purple color means approximately $150 \mathrm{mmHg}$ (arrow).

to Chicago classification, this patient was categorized as achalasia type II due to elevated integrated relaxation pressure and panesophageal pressurization. ${ }^{1}$ The interesting point is amazingly high panesophageal pressurization represented by red color, 80 to $120 \mathrm{mmHg}$, and dark purple color, $150 \mathrm{mmHg}$ (Fig. 2B). This dramatic high-resolution manometry finding can explain why the lumen of the lower esophagus was nearly collapsed, and why it was so hard to advance an endoscope through the lower esophagus, even more difficult than to pass esophagogastric junction.
He underwent peroral endoscopic myotomy, $10 \mathrm{~cm}$ in length. Eckardt symptom score decreased to 3 from 5 , and he could swallow soft and solid diet.

\section{Reference}

1. Bredenoord AJ, Fox M, Kahrilas PJ, et al. Chicago classification criteria of esophageal motility disorders defined in high resolution esophageal pressure topography. Neurogastroenterol Motil 2012;24(suppl 1):57-65. 